Article

\title{
Dufour Effect with Ramped Wall Temperature and Specie Concentration on Natural Convection Flow through a Channel
}

\author{
Basant Kumar Jha ${ }^{1}$ and Yusuf Ya'u Gambo ${ }^{1,2, *(1)}$ \\ 1 Department of Mathematics, Ahmadu Bello University, P.M.B. 1045 Zaria, Nigeria; basant777@yahoo.co.uk \\ 2 Department of Mathematics, Yusuf Maitama Sule University, P.M.B. 3220 Kano, Nigeria \\ * Correspondence: yygambo@gmail.com; Tel.: +234-8065-899-446
}

Received: 6 April 2019; Accepted: 23 May 2019; Published: 28 May 2019

\begin{abstract}
In this paper, we have obtained an analytical solution to the problem of unsteady free convection and mass transfer flow of an incompressible fluid through a vertical channel in the presence of Dufour effect (or diffusion thermo). The bounding plates are assumed to have ramped wall temperature as well as specie concentration. The mathematical model responsible for the physical situation is presented in dimensionless form and solved analytically using the powerful Laplace Transform Technique (LTT) under relevant initial and boundary conditions. In order to cross check the accuracy of the analytical results, numerical solutions are obtained using PDEPE solver in MATLAB. The expressions for temperature, concentration, and velocity are obtained. The effects of Dufour parameter, Prandtl number $(\mathrm{Pr})$, Schmidt number $(\mathrm{Sc})$, and dimensionless time are described during the course of these discussions. The temperature, concentration, and velocity profiles are graphically presented for some realistic values of $\operatorname{Pr}=0.025,0.71,7.0,11.62,100.0$ and $S c=0.22,0.60,1.00,2.62$, while the values of all other parameters are arbitrarily taken.
\end{abstract}

Keywords: natural convection; mass transfer; ramped temperature and concentration; Laplace Transform Technique

\section{Introduction}

Fluid flow, and the combined heat and mass transfer through a channel, have received less attention than the case of a single plate. This configuration is very frequently encountered in numerous applications, such as fire engineering, combustion modelling, nuclear energy, petroleum reservoir etc. Transport phenomena, involving the combined influence of thermal and concentration buoyancy, are often seen in many engineering systems. They are frequently encountered in the design of modern electric circuits, heat exchangers, solar panels, ventilation system in buildings, chemical distilleries, and thermal protection systems [1-11]. Most of these studies are directed towards the effects of various fluid dynamical processes and flow geometry. Moreover, most of the previous studies were carried out by either numerical or experimental methods.

Study on free convection flow, due to the effect of temperature change has drawn significant interest recently [12-16]. Authors in [17] formulated the problem of coupled heat and mass transfer by natural convection from a vertical, semi-infinite flat plate, embedded in a porous medium in the presence of an external magnetic field and internal heat generation or absorption effects. In this paper, the plate surface was maintained at either, constant temperature or constant heat flux, and was permeable to allow for possible fluid wall suction or blowing. Chamkha [18] considered unsteady, laminar, double-diffusive, natural convection flow inside a rectangular enclosure filled with a uniform porous medium with cooperating temperature and concentration gradients. Ismail et al. [19] investigated 
unsteady magnetohydrodynamics natural convection flow through a porous medium, with ramped boundary conditions, over an infinite inclined wall in the presence of thermal radiation. Authors in [20] showed how heat and mass transfer were affected, by introducing a perfectly thin conducting baffle in a vertical channel, filled with electrically conducting and chemically reacting fluid. After inserting the baffle, the fluid is concentrated in each stream with different chemically reacting agents. The basic governing equations were solved by perturbation method and also by Differential Transformation Method (DTM). The effects of Joule-heating, chemical reactions, and thermal radiation on unsteady magnetohydrodynamic (MHD) natural convection, from a heated vertical porous plate in a micropolar fluid, were analyzed by [21]. The partial differential equations, governing the flow and heat and mass transfer, were solved numerically using an implicit finite-difference scheme. The case corresponding to vanishing of the anti-symmetric part of the stress tensor, that represents weak concentrations, was considered. Authors in [22] studied the steady laminar magneto-hydrodynamic thermosolutal Marangoni convection, in the presence of a uniform applied magnetic field, in the boundary layer approximation. They assumed that the surface tension varies linearly with both the temperature and concentration, and that the interface temperature and concentration are quadratic functions of the interface arc length $x$. Exact analytical solutions for the velocity, temperature, and concentration boundary layers were obtained.

Two important phenomena in heat and mass transfer processes are Dufour and Soret effects. Dufour effect (also diffusion-thermo) is the transfer of heat, generated by a concentration gradient, while Soret effect (also thermal diffusion) is the mass transfer generated by temperature gradient. When compared to the effect illustrated by Fourier's or Fick's law, the magnitudes of Dufour and Soret effects are smaller and usually considered negligible [23]. Nonetheless, these effects have enormous applications, such as in separation of isotopes and in mixing gases of insubstantial and average molecular weights [24]. Jha and Ajibade [25] analytically investigated the free-convection and mass transfer flow in a vertical channel formed by two vertical parallel plates. Fully developed laminar flow was considered with uniform temperature and concentration on the plates. The Dufour effect was taken into consideration. The analytical solutions for velocity, temperature, and concentration were obtained, using LTT and were used to compute the shear stress, Nusselt number, and mass flux. In [26], the authors investigated Dufour and Soret effects on mass transfer flow within the boundary layer, with mixed free-forced convection. The observation they made was that the occurrence of heat and mass transfer concurrently, in non-static fluids, makes the relationship between the driving force and fluxes more complex. They concluded that it is possible to produce an energy flux by concentration gradients too. Sheremet [27] numerically analyzed the influence of Dufour and Soret effects, on non-stationary regimes of conjugate convective heat and mass transfer in an enclosure, in the presence of heat conductive walls of finite thickness. Authors in [28] presented a numerical solution to the general problem of MHD flow, heat, and mass transfer of viscous incompressible nano-fluid past a uniformly stretching sheet through a porous media with heat generation/absorption, thermal radiation, chemical reaction, Dufour effect, and Soret effect.

Practical problems often involve wall conditions that are non-uniform or arbitrary. To understand such problems, it is useful to investigate problems which are subjected to step change in wall temperature. Several attempts in this direction were made by various authors. In [29], the authors investigated the natural convective flow through double infinite vertical walls having ramped temperature at one boundary with specie concentration as well as thermal radiation. In this paper, the analysis on the influence of some embedded parameters was presented. By applying LTT and including ramped wall temperature condition, Asma et al. [30] carried out research on natural convective flow of nanofluids past an oscillating wall. The ramped and isothermal cases were compared. Authors in [31] studied the free convection flow over a single vertical wall with ramped wall temperature. Narahari and Raghavan [32] obtained an analytical solution to the free convective flow, of an incompressible fluid through a channel, as a result of ramped heating at one boundary using LTT. Narahari et al. [33] presented the effect of ramped temperature on unsteady MHD natural convection flow past an infinite 
inclined plate in the presence of radiation, heat source, and chemical reaction. The natural convection due to ramped wall temperature was also compared with that of the isothermal plate. It was found that the velocity and skin friction decreases with increasing radiation parameter, magnetic field parameter, and the angle of inclination in both ramped and isothermal cases. The authors in [12] investigated the Dufour effect on free convective flow with heat absorption, thermal radiation, chemical reaction, and magnetic field with ramped wall temperature over a single vertical plate contained in a permeable medium.

The objective of the present work is to provide an analytical solution for the unsteady free convection and mass transfer flow, in a vertical channel, with ramped wall temperature and ramped wall specie concentration, in the presence of Dufour effect. The influences of the ramped walls are analysed with different parameters embedded in the problem. The main benefits resulting from the analytical approach is a transparent dependence of the quantity of engineering interest of the governing parameters. The accuracy of the analytical solutions is ensured by making a comparison with the numerical solutions. Furthermore, the results presented here are compared with existing literature Singh et al. [34], where the boundary conditions are constant and Dufour effect is absent. In fact, the solutions obtained by Singh et al. is a particular case of the solutions obtained in the present work. The present results will have specific applications in the design of solar energy collectors, geothermal systems, cooling of electronic equipment, and in the design of chemical processing equipment.

\section{Governing Equations}

Mathematical model responsible for transient free convection and mass transfer flow in a vertical channel in the presence Dufour effect is considered. Let $x$-axis be along the vertical direction and $y$-axis normal to it (Figure 1).

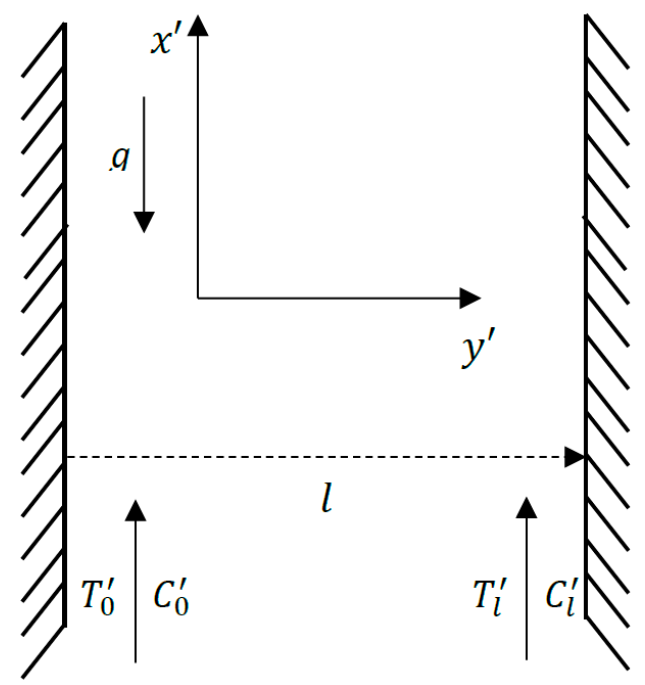

Figure 1. Physical configuration.

At the initial state $t^{\prime} \leq 0$, the two bounding walls as well as the fluid are at rest and considered to have the same constant temperature $T_{l}^{\prime}$ and concentration $C_{l}^{\prime}$. At $t^{\prime}>0$, the temperature and concentration at the wall $y^{\prime}=0$ have, respectively, a temporally ramped function given by $T_{l}^{\prime}+$ $\left(T_{0}^{\prime}-T_{l}^{\prime}\right) t^{\prime} / t_{0}$ and $C_{l}^{\prime}+\left(C_{0}^{\prime}-C_{l}^{\prime}\right) t^{\prime} / t_{0}$ at $t^{\prime} \leq t_{0}$, and then, at $t^{\prime}>t_{0}$, the temperature and concentration are maintained at $T_{0}^{\prime}$ and $C_{0}^{\prime}$ respectively. The temperature and concentration at the other wall $y^{\prime}=l$ remain the same as the initial temperature $T_{l}^{\prime}$ and concentration $C_{l}^{\prime}$ giving raise to free convection currents. The system of equations shows that the temperature is influenced by specie concentration which leads to Dufour effect. We presume that the heat flux that radiates along the vertical axis is negligible relative to that along the horizontal axis. Since both the two walls are of infinite length, all 
the physical quantities will depend only upon $y^{\prime}$ and $t^{\prime}$. Within the framework of such assumptions, the equations which govern free convection and mass transfer flow in the presence of Dufour effect under Boussinesq approximation are:

$$
\begin{gathered}
\frac{\partial u^{\prime}}{\partial t^{\prime}}=v \frac{\partial^{2} u^{\prime}}{\partial y^{\prime 2}}+g \beta\left(T^{\prime}-T_{l}^{\prime}\right)+g \beta^{*}\left(C^{\prime}-C_{l}^{\prime}\right) \\
\frac{\partial T^{\prime}}{\partial t^{\prime}}=\alpha \frac{\partial^{2} T^{\prime}}{\partial y^{\prime 2}}+D^{*} \frac{\partial^{2} C^{\prime}}{\partial y^{\prime 2}} \\
\frac{\partial C^{\prime}}{\partial t^{\prime}}=D_{m} \frac{\partial^{2} C^{\prime}}{\partial y^{\prime 2}}
\end{gathered}
$$

Subject to the following initial and boundary conditions

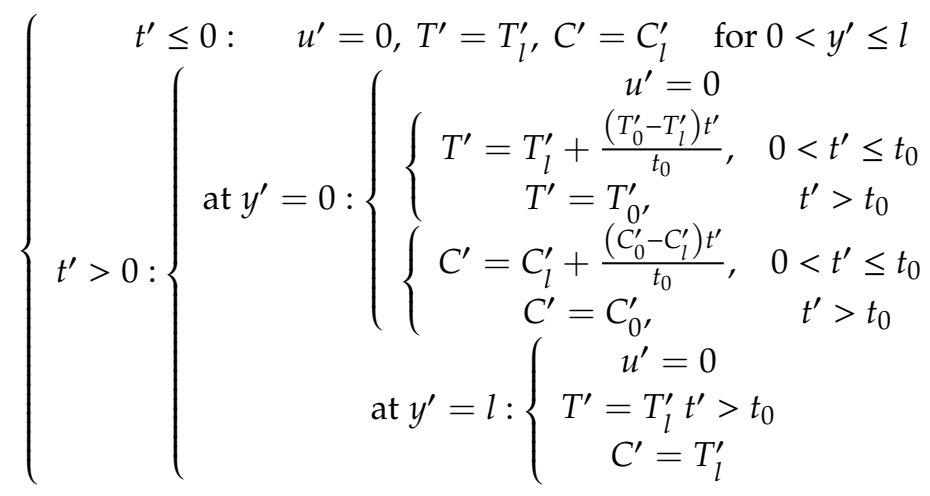

To change Equations (1)-(3) to non-dimensional forms, we make the following substitutions:

$$
\left.\begin{array}{c}
t=\frac{t^{\prime}}{t_{0}}, t_{0}=\frac{l^{2}}{v}, y=\frac{y^{\prime}}{l}, \quad \operatorname{Pr}=\frac{v}{\alpha}, \\
\theta=\frac{T^{\prime}-T_{l}^{\prime}}{T_{0}-T_{l}^{\prime}}, \phi=\frac{C^{\prime}-C_{l}^{\prime}}{C_{0}-C_{l}^{\prime}}, \quad u=\frac{u^{\prime} v}{g \beta\left(T_{0}^{\prime}-T_{l}^{\prime}\right) l^{2}}, \\
D_{f}=\frac{D^{*}\left(C_{0}^{\prime}-C_{l}^{\prime}\right)}{T_{0}^{\prime}-T_{l}^{\prime}}, \quad S c=\frac{v}{D_{m}}, N=\frac{\beta^{*}\left(C_{0}^{\prime}-C_{l}^{\prime}\right)}{\beta\left(T_{0}^{\prime}-T_{l}^{\prime}\right)} .
\end{array}\right\}
$$

Thus, Equations (1)-(3) can be written as

$$
\begin{gathered}
\frac{\partial u}{\partial t}=\frac{\partial^{2} u}{\partial y^{2}}+\theta+N \phi \\
\frac{\partial \theta}{\partial t}=\frac{1}{\operatorname{Pr}} \frac{\partial^{2} \theta}{\partial y^{2}}+\frac{D_{f}}{\operatorname{Pr}} \frac{\partial^{2} \phi}{\partial y^{2}} \\
\frac{\partial \phi}{\partial t}=\frac{1}{S c} \frac{\partial^{2} \phi}{\partial y^{2}}
\end{gathered}
$$

Therefore, Equation (4) becomes 


$$
\begin{gathered}
t \leq 0: \quad u(t, y)=0, \theta(t, y)=0, \phi(t, y)=0 ; \quad 0 \leq y \leq 1 \\
u(t, 0)=0, u(t, 1)=0 \\
t>0:\left\{\begin{array}{c}
\theta(t, 0)=t, \quad \phi(t, 0)=t ; \quad 0<t \leq 1 \\
\theta(t, 0)=1, \quad \phi(t, 0)=1 ; \quad t>1 \\
\theta(t, 1)=\phi(t, 1)=0
\end{array}\right.
\end{gathered}
$$

The heat transfer coefficient $(\mathrm{Nu})$, mass transfer coefficient $(\mathrm{Sh})$ and the coefficient of Skin-friction $\left(C_{f}\right)$ are vital numbers in the study of boundary layer flow and are defined respectively as

$$
\begin{aligned}
& C_{f}=-\left(\frac{\partial u}{\partial y}\right)_{y=0} \\
& N u=-\left(\frac{\partial \theta}{\partial y}\right)_{y=0} \\
& S h=-\left(\frac{\partial \phi}{\partial y}\right)_{y=0}
\end{aligned}
$$

\section{Solutions}

The ramped BCs for temperature and concentration given in Equation (9) can be written in linear form using the Heaviside step function $H(t)$ as

$$
\theta(t, 0)=\phi(t, 0)=t[H(t)]-(t-1)[H(t-1)]
$$

Then applying LTT to (6)-(8) in conjunction with (9) and taking (13) into consideration we obtain

$$
\begin{gathered}
\theta(\omega, y)=\left(\frac{1-e^{-\omega}}{\omega^{2}}\right) \sum_{k=0}^{\infty}\left\{\rho_{1}\left[e^{-(2 k+y) \sqrt{\omega P r}}-e^{-(2+2 k-y) \sqrt{\omega P r}}\right]\right. \\
\left.-\rho_{2}\left[e^{-(2 k+y) \sqrt{\omega S c}}-e^{-(2+2 k-y) \sqrt{\omega S c}}\right]\right\} \\
\phi(\omega, y)=\left(\frac{1-e^{-\omega}}{\omega^{2}}\right) \sum_{k=0}^{\infty}\left[e^{-(2 k+y) \sqrt{\omega S c}}-e^{-(2+2 k-y) \sqrt{\omega S c}}\right] \\
u(\omega, y)=\left(\frac{1-e^{-\omega}}{\omega^{2}}\right) \sum_{k=0}^{\infty}\left\{\sigma_{1}\left[e^{-(2 k+y) \sqrt{\omega}}-e^{-(2+2 k-y) \sqrt{\omega}}\right]\right. \\
-\sigma_{2}\left[e^{-(2 k+y) \sqrt{\omega S c}}-e^{-(2+2 k-y) \sqrt{\omega S c}}\right] \\
\left.-\sigma_{3}\left[e^{-(2 k+y) \sqrt{\omega P r}}-e^{-(2+2 k-y) \sqrt{\omega P r}}\right]\right\}
\end{gathered}
$$

where, $\omega$ denotes the Laplace parameter and

$$
\begin{gathered}
\rho_{1}=\frac{1+D_{f} S c}{S c-P r} \\
\rho_{2}=\frac{D_{f} S c}{S c-P r} \\
\sigma_{1}=\left(N-\frac{D_{f} S c}{S c-P r}\right)\left(\frac{1}{S c-1}\right)+\left(\frac{1}{P r-1}\right)\left(1+\frac{D_{f} S c}{S c-P r}\right) \\
\sigma_{2}=\left(N-\frac{D_{f} S c}{S c-P r}\right)\left(\frac{1}{S c-1}\right) \\
\sigma_{3}=\left(\frac{1}{P r-1}\right)\left(1+\frac{D_{f} S c}{S c-P r}\right) \\
P r \neq S c \neq 1
\end{gathered}
$$


By taking the inverse transforms of (14)-(16) and applying the second shift theorem [35-37], we obtain the following solutions:

$$
\begin{aligned}
& \theta(t, y)= \sum_{k=0}^{\infty}\left\{\rho_{1}\left[G_{1}(t, y)-G_{2}(t, y)-G_{1}(t-1, y)-G_{2}(t-1, y) H(t-1)\right]\right. \\
&\left.-\rho_{2}\left[G_{3}(t, y)-G_{4}(t, y)-G_{3}(t-1, y)-G_{4}(t-1, y) H(t-1)\right]\right\} \\
& \phi(t, y)=\sum_{k=0}^{\infty}\left\{\Upsilon_{1}(t, y)-\Upsilon_{2}(t, y)-\left[\Upsilon_{1}(t-1, y)-\Upsilon_{2}(t-1, y)\right][H(t-1)]\right\} \\
& u(t, y)=\sum_{k=0}^{\infty}\left\{\sigma_{1}\left[L_{1}(t, y)-L_{2}(t, y)-L_{1}(t-1, y)-L_{2}(t-1, y) H(t-1)\right]\right. \\
&-\sigma_{2}\left[L_{3}(t, y)-L_{4}(t, y)-L_{3}(t-1, y)-L_{4}(t-1, y) H(t-1)\right] \\
&-\sigma_{3}\left[L_{5}(t, y)-L_{6}(t, y)-L_{5}(t-1, y)-L_{6}(t-1, y) H(t-1)\right\}
\end{aligned}
$$

where

$$
\begin{aligned}
& \Upsilon_{1}(t, y)=\left[t+\frac{S c(2 k+y)^{2}}{2}\right] \operatorname{erfc}\left(\frac{\sqrt{S c}(2 k+y)}{2 \sqrt{t}}\right)-\sqrt{\frac{t S c}{\pi}}(2 k \\
& +y) \exp \left(-\frac{S c(2 k+y)^{2}}{4 t}\right) \\
& \Upsilon_{2}(t, y)=\left[t+\frac{S c(2+2 k-y)^{2}}{2}\right] \operatorname{erfc}\left(\frac{\sqrt{S c}(2+2 k-y)}{2 \sqrt{t}}\right)-\sqrt{\frac{t S c}{\pi}}(2+2 k \\
& -y) \exp \left(-\frac{s c(2+2 k-y)^{2}}{4 t}\right) \\
& G_{1}(t, y)=\left[t+\frac{\operatorname{Pr}(2 k+y)^{2}}{2}\right] \operatorname{erfc}\left(\frac{\sqrt{\operatorname{Pr}}(2 k+y)}{2 \sqrt{t}}\right)-\sqrt{\frac{t P r}{\pi}}(2 k \\
& +y) \exp \left(-\frac{\operatorname{Pr}(2 k+y)^{2}}{4 t}\right) \\
& G_{2}(t, y)=\left[t+\frac{\operatorname{Pr}(2+2 k-y)^{2}}{2}\right] \operatorname{erfc}\left(\frac{\sqrt{P r}(2+2 k-y)}{2 \sqrt{t}}\right)-\sqrt{\frac{t P r}{\pi}}(2+2 k \\
& -y) \exp \left(-\frac{\operatorname{Pr}(2+2 k-y)^{2}}{4 t}\right) \\
& G_{3}(t, y)=\Upsilon_{1}(t, y) \\
& G_{4}(t, y)=\Upsilon_{2}(t, y) \\
& L_{1}(t, y)=\frac{1}{2}\left[\frac{(2 k+y)^{4}}{12}+(2 k+y)^{2} t+t^{2}\right] \operatorname{erfc}\left(\frac{2 k+y}{2 \sqrt{t}}\right)-\frac{1}{6} \sqrt{\frac{t}{\pi}}(2 k \\
& +y)\left[\frac{(2 k+y)^{2}}{2}+5 t\right] \exp \left(-\frac{(2 k+y)^{2}}{4 t}\right) \\
& L_{2}(t, y)=\frac{1}{2}\left[\frac{(2+2 k-y)^{4}}{12}+(2+2 k-y)^{2} t+t^{2}\right] \operatorname{erfc}\left(\frac{2+2 k-y}{2 \sqrt{t}}\right) \\
& -\frac{1}{6} \sqrt{\frac{t}{\pi}}(2+2 k-y)\left[\frac{(2+2 k-y)^{2}}{2}\right. \\
& +5 t] \exp \left(-\frac{(2+2 k-y)^{2}}{4 t}\right) \\
& L_{3}(t, y)=\frac{1}{2}\left[\frac{S c^{2}(2 k+y)^{4}}{12}+S c(2 k+y)^{2} t+t^{2}\right] \operatorname{erfc}\left(\frac{\sqrt{S c}(2 k+y)}{2 \sqrt{t}}\right) \\
& -\frac{1}{6} \sqrt{\frac{t S c}{\pi}}(2 k+y)\left[\frac{S c(2 k+y)^{2}}{2}+5 t\right] \exp \left(-\frac{S c(2 k+y)^{2}}{4 t}\right)
\end{aligned}
$$




$$
\begin{gathered}
L_{4}(t, y)=\quad \begin{array}{c}
\frac{1}{2}\left[\frac{S c^{2}(2+2 k-y)^{4}}{12}+S c(2+2 k-y)^{2} t\right. \\
\left.+t^{2}\right] \operatorname{erfc}\left(\frac{\sqrt{S c}(2+2 k-y)}{2 \sqrt{t}}\right)
\end{array} \\
-\frac{1}{6} \sqrt{\frac{t S c}{\pi}}(2+2 k-y)\left[\frac{S c(2+2 k-y)^{2}}{2}\right. \\
+5 t] \exp \left(-\frac{S c(2+2 k-y)^{2}}{4 t}\right)
\end{gathered}
$$

3.1. Solution for the Temperature When $\mathrm{Pr}=S \mathrm{C}$

It can be observed in (18) that the solution for temperature does not hold when the Prandtl and Schmidt numbers are the same. However, setting $\operatorname{Pr}=S c$ right from (8) we obtain

$$
\begin{aligned}
\theta(t, y)=\sum_{k=0}^{\infty}\left\{D_{f} \sqrt{S c}(k+1)\left[P_{4}(t, y)-P_{2}(t, y)\right]+P_{3}(t, y)-P_{1}(t, y)\right. \\
+\left[P_{1}(t-1, y)-P_{3}(t-1, y)\right. \\
\left.\left.+D_{f} \sqrt{S c}(k+1) P_{2}(t-1, y)-P_{4}(t-1, y)\right][H(t-1)]\right\}
\end{aligned}
$$

where

$$
\begin{gathered}
P_{1}(t, y)=\left[t+\frac{S c(2+2 k-y)^{2}}{2}\right] \operatorname{erfc}\left(\frac{\sqrt{S c}(2+2 k-y)}{2 \sqrt{t}}\right)- \\
\sqrt{\frac{t S c}{\pi}}(2+2 k-y) \exp \left(-\frac{S c(2+2 k-y)^{2}}{4 t}\right) \\
P_{2}(t, y)=\quad 2 \sqrt{\frac{t}{\pi}} \exp \left(-\frac{S c(2+2 k-y)^{2}}{4 t}\right) \\
P_{3}(t, y)=\left[t+\frac{S c(2 k+y)^{2}}{2}\right] \operatorname{erfc}\left(\frac{\sqrt{S c}(2 k+y)}{2 \sqrt{t}}\right)- \\
P_{4}(t, y)=2 \sqrt{\frac{t S c}{\pi}}(2 k+y) \exp \left(-\frac{S c(2 k+y)^{2}}{4 t}\right) \\
\sqrt{\frac{t}{\pi}} \exp \left(-\frac{S c(2 k+y)^{2}}{4 t}\right)-\sqrt{S c}(2 k+y) \operatorname{erfc}\left(\frac{\sqrt{S c}(2 k+y)}{2 \sqrt{t}}\right)
\end{gathered}
$$


3.2. Solution for the Velocity When $\operatorname{Pr}=S c \neq 1$

It is clear that (20) does not hold when $\operatorname{Pr}=S c \neq 1$. Thus, if $\operatorname{Pr} \neq 1$, then putting $\operatorname{Pr}=S c$ in (6)-(8), the solution for velocity becomes

$$
\begin{aligned}
& u(t, y)=\frac{1}{P r-1} \quad \sum_{k=0}^{\infty}\left\{(N+1)\left[Q_{1}(t, y)-Q_{3}(t, y)+Q_{5}(t, y)-Q_{7}(t, y)\right]\right. \\
& +(k+1) D_{f} \sqrt{\operatorname{Pr}}\left[Q_{2}(t, y)-Q_{4}(t, y)+Q_{6}(t, y)-Q_{8}(t, y)\right] \\
& +(N+1) Q_{3}(t-1, y)-Q_{1}(t-1, y)+Q_{7}(t-1, y)-Q_{5}(t-1, y) \\
& +(k+1) D_{f} \sqrt{\operatorname{Pr}} Q_{4}(t-1, y)-Q_{2}(t-1, y)+Q_{8}(t-1, y) \\
& \left.\left.-Q_{6}(t-1, y)\right][H(T-1)]\right\}
\end{aligned}
$$

Here

$$
\begin{aligned}
& Q_{1}(t, y)=L_{1}(t, y) \\
& Q_{2}(t, y)=\frac{1}{3}\left[4 t+(2 k+y)^{2}\right] \sqrt{\frac{t}{\pi}} \exp \left(-\frac{(2 k+y)^{2}}{4 t}\right) \\
& -\left[\frac{(2 k+y)^{3}}{6}+(2 k+y) t\right] \operatorname{erfc}\left(\frac{2 k+y}{2 \sqrt{t}}\right) \\
& Q_{3}(t, y)=L_{2}(t, y) \\
& Q_{4}(t, y)=\frac{1}{3}\left[4 t+(2+2 k-y)^{2}\right] \sqrt{\frac{t}{\pi}} \exp \left(-\frac{(2+2 k-y)^{2}}{4 t}\right) \\
& -\left[\frac{(2+2 k-y)^{3}}{6}+(2+2 k-y) t\right] \operatorname{erfc}\left(\frac{2+2 k-y}{2 \sqrt{t}}\right) \\
& Q_{5}(t, y)=L_{4}(t, y) \\
& Q_{6}(t, y)=\quad \frac{1}{3}\left[4 t+\operatorname{Pr}(2+2 k-y)^{2}\right] \sqrt{\frac{t}{\pi}} \exp \left(-\frac{\operatorname{Pr}(2+2 k-y)^{2}}{4 t}\right) \\
& -\left[\frac{\operatorname{Pr} \frac{3}{2}(2+2 k-y)^{3}}{6}+\sqrt{\operatorname{Pr}}(2+2 k-y) t\right] \operatorname{erfc}\left(\frac{\sqrt{\operatorname{Pr}}(2+2 k-y)}{2 \sqrt{t}}\right) \\
& Q_{7}(t, y)=L_{3}(t, y) \\
& Q_{8}(t, y)=\frac{1}{3}\left[4 t+\operatorname{Pr}(2 k+y)^{2}\right] \sqrt{\frac{t}{\pi}} \exp \left(-\frac{\operatorname{Pr}(2 k+y)^{2}}{4 t}\right) \\
& -\left[\frac{\operatorname{Pr}^{\frac{3}{2}}(2 k+y)^{3}}{6}+\sqrt{\operatorname{Pr}}(2 k+y) t\right] \operatorname{erfc}\left(\frac{\sqrt{\operatorname{Pr}}(2 k+y)}{2 \sqrt{t}}\right)
\end{aligned}
$$

3.3. Solution for the Velocity When $\operatorname{Pr}=S c=1$

In the case of fluids with $P r=S c=1$, then

$$
u(t, y)=y \sum_{k=0}^{\infty} \begin{gathered}
\left\{\left(\frac{1+N}{2}\right)\left[W_{1}(t, y)-W_{3}(t, y)\right]\right. \\
+(k+1) D_{f}\left[W_{2}(t, y)-W_{4}(t, y)\right] \\
+\left[\left(\frac{1+N}{2}\right) W_{3}(t-1, y)-W_{1}(t-1, y)\right. \\
\left.\left.+(k+1) D_{f} W_{4}(t-1, y)-W_{2}(t-1, y)\right] H(T-1)\right\}
\end{gathered}
$$


Here,

$$
\begin{gathered}
W_{1}(t, y)=Q_{4}(t, y) \\
W_{2}(t, y)=\left[t+\frac{(2+2 k-y)^{2}}{2}\right] \operatorname{erfc}\left(\frac{2+2 k-y}{2 \sqrt{t}}\right)- \\
\sqrt{\frac{t}{\pi}}(2+2 k-y) \exp \left(-\frac{(2+2 k-y)^{2}}{4 t}\right) \\
W_{3}(t, y)=Q_{2}(t, y) \\
W_{2}(t, y)=\left[t+\frac{(2 k+y)^{2}}{2}\right] \operatorname{erfc}\left(\frac{2 k+y}{2 \sqrt{t}}\right)- \\
\sqrt{\frac{t}{\pi}}(2 k+y) \exp \left(-\frac{(2 k+y)^{2}}{4 t}\right)
\end{gathered}
$$

\section{Results and Discussions}

The Dufour effect on the flow of a viscous fluid, through a vertical channel with ramped boundary conditions, is investigated. The analytical and numerical solutions to the system of governing Equations (6)-(8) with appropriate ICs and BCs given in (9) have been obtained using LTT and pdepe in MATLAB respectively. The results are obtained by varying the values of the embedded parameters. The buoyancy ratio $(N)$ and Dufour parameter $\left(D_{f}\right)$ are arbitrarily taken. During the course of numerical computations of the velocity, temperature, concentration, coefficient of skin-friction, coefficient of heat transfer and coefficient of mass transfer, the values of Prandtl number are chosen for Mercury $(P r=0.025)$, air $(P r=0.71)$, water $(P r=7.0)$, water at $4{ }^{\circ} \mathrm{C}(\operatorname{Pr}=11.62)$ and engine oil $(P r=100)$. Similarly, the values of $S c$ are chosen for the gases representing diffusing chemical species of most common interest in air namely hydrogen $(S c=0.22)$, water-vapour $(S c=0.60)$, ammonia $(S c=0.78)$, methanol $(S c=1.00)$ and propyl-benzene $(S c=2.62)$ at $20{ }^{\circ} \mathrm{C}$ and one atmospheric pressure [38].

The solutions for temperature, concentration, velocity, Nuselt number, Sherwood number and wall Skin-friction are graphically reported in Figures 2-14, thereby revealing the influence of the embedded parameters on the flow.

In order to highlight the accuracy of the analytical and numerical results, comparison is made and presented in Table 1. From the table, it is clear that the analytical and numerical results are in good agreement.

From Figure 2, it can be observed that the temperature descents from the ramped state on the wall to the free stream state. As $t$ increases, the temperature also increases. Likewise, when the Schmidt number increases, the temperature rises as well for all $t$. In Figure 3, concentration is seen to reduce as the Schmidt number increases, while it increases with increase in time.

Table 1. Comparison of numerical and analytical results for temperature $(\theta)$, concentration $(\phi)$ and velocity $(u)$ profiles for $N=2, \operatorname{Pr}=0.71, S c=0.78, D_{f}=0.01, t=0.8$.

\begin{tabular}{ccccccc}
\hline \multirow{2}{*}{$\boldsymbol{y}$} & \multicolumn{3}{c}{ Numerical Solution } & \multicolumn{3}{c}{ Analytical Solution } \\
\cline { 2 - 7 } & $\boldsymbol{\theta}$ & $\boldsymbol{\phi}$ & $\boldsymbol{u}$ & $\boldsymbol{\theta}$ & $\boldsymbol{\phi}$ & $\boldsymbol{u}$ \\
\hline 0.00 & 0.80000 & 0.80000 & 0.00000 & 0.80000 & 0.80000 & 0.00000 \\
0.25 & 0.56160 & 0.55735 & 0.10584 & 0.56160 & 0.55735 & 0.10579 \\
0.50 & 0.35611 & 0.35125 & 0.11583 & 0.35611 & 0.35125 & 0.11577 \\
0.75 & 0.17257 & 0.16953 & 0.07047 & 0.17257 & 0.16953 & 0.07043 \\
1.00 & 0.00000 & 0.00000 & 0.00000 & 0.00000 & 0.00000 & 0.00000 \\
\hline
\end{tabular}




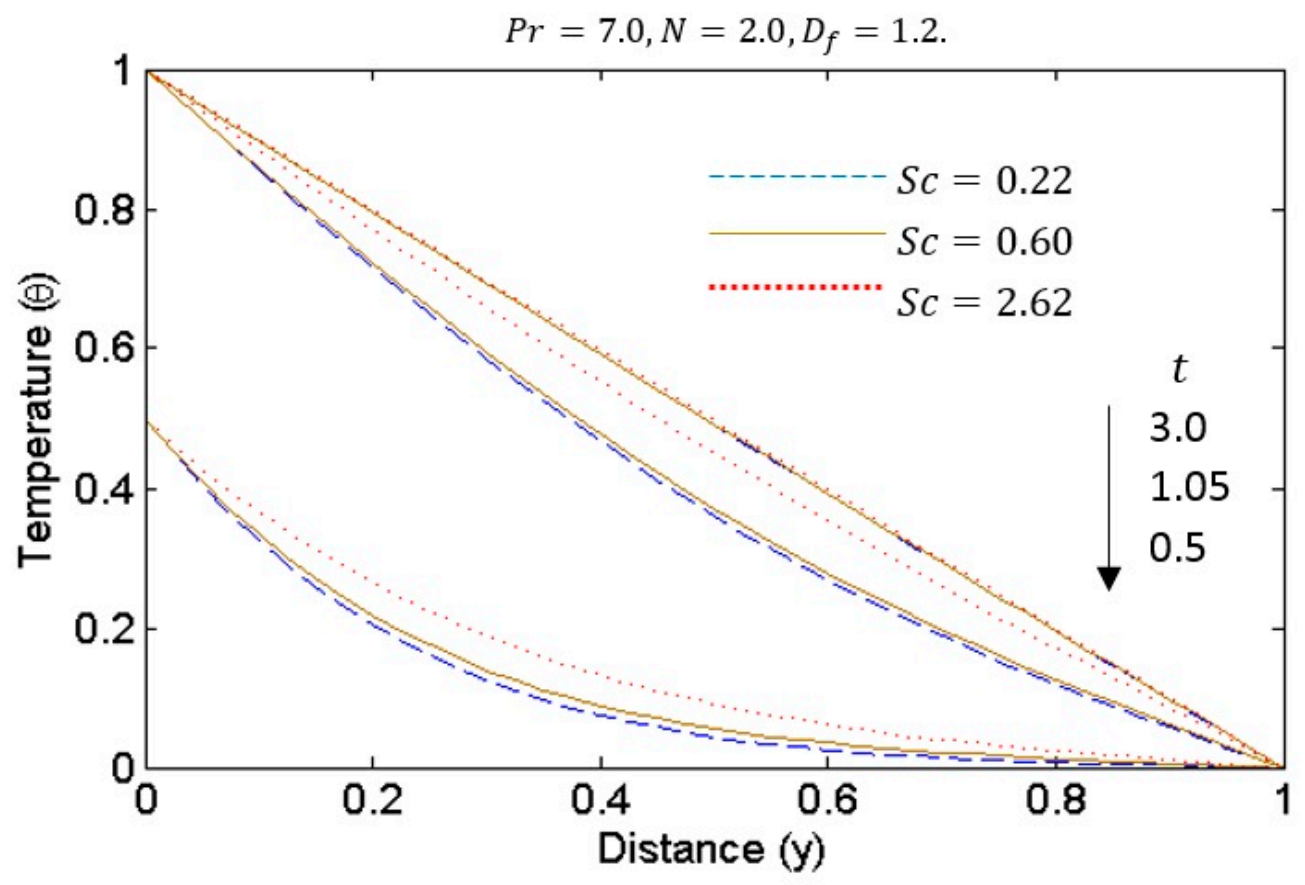

Figure 2. Temperature profile for various $t$ and Sc.

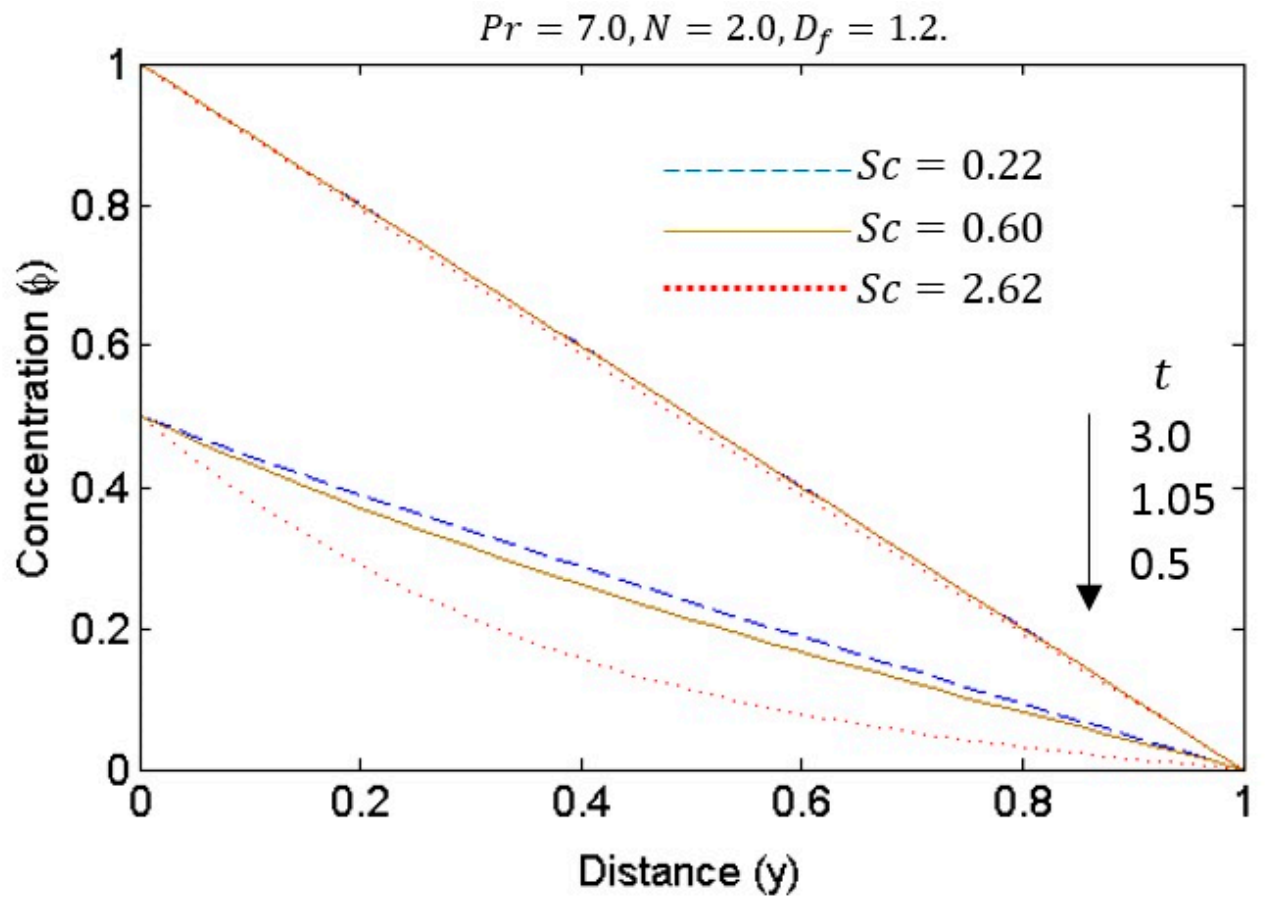

Figure 3. Concentration profile for various $t$ and Sc.

Figure 4 shows that the isothermal wall temperature is greater than the ramped wall temperature (or they are at least the same). This happens because heating of the fluid takes place more slowly in the case of ramped boundary conditions than the case of constant boundary conditions. 
Similarly, it can be seen in Figure 5, that the species concentration is greater in the case of isothermal plate than in the case of ramped temperature at the plate. However, it is observed that the fluid temperature demonstrates significant change over time than the concentration.

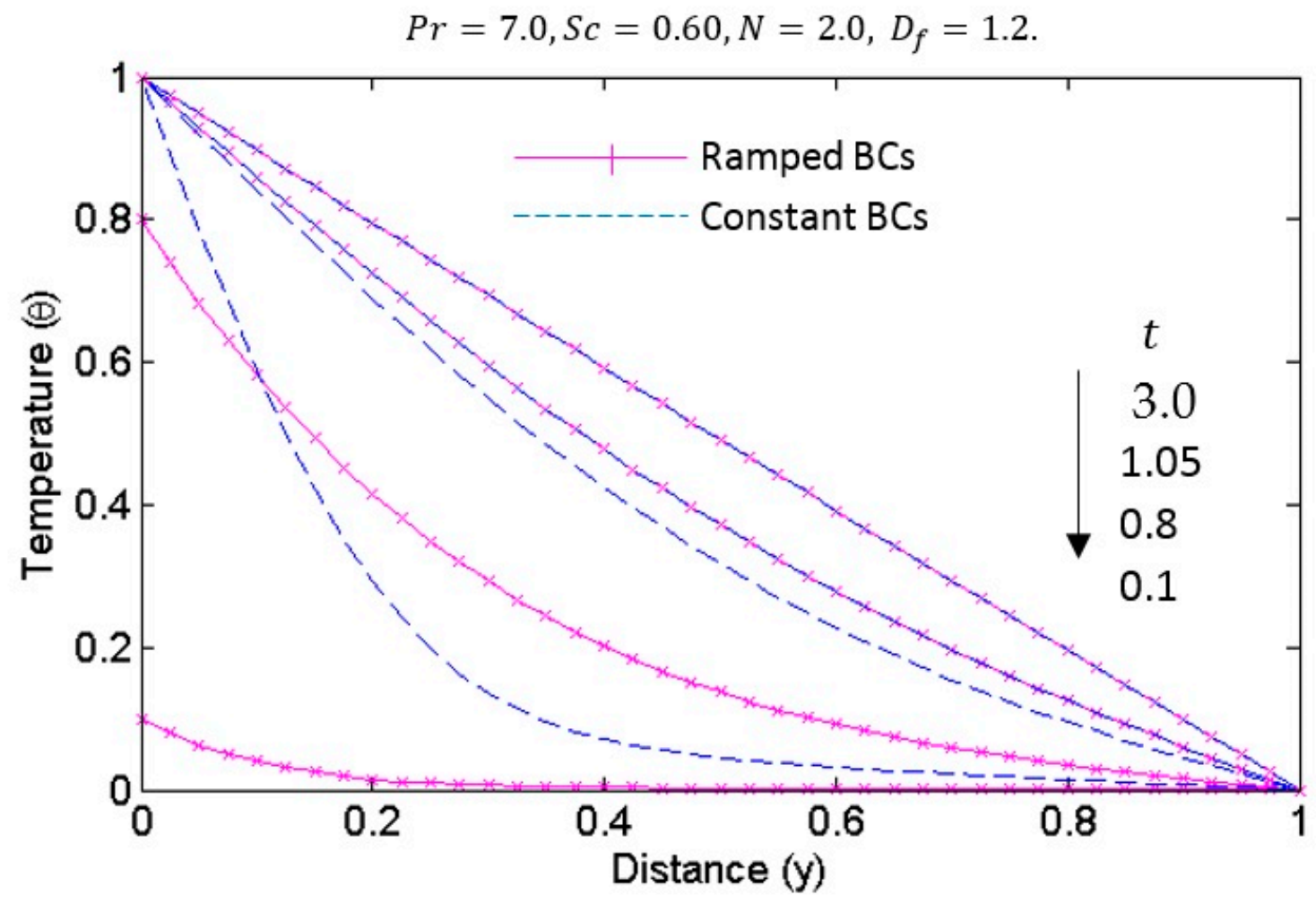

Figure 4. Temperature profile with ramped and constant boundary conditions.

Dufour effect with both ramped and constant boundary conditions are respectively presented in Figures 6-9. It is observed that the temperature rises when $t$ and $D_{f}$ increase. Moreover, the particular case of $D_{f}=0$ in Figure 8 corresponds to the work of Singh et al. [34] and it indicates that the energy flux is not caused by specie concentration gradient. Thus, we see that Dufour effect has the tendency to change the fluid's temperature. So also, it is clear that the temperature is higher in the case of constant boundary conditions compared to when ramped wall conditions are used since heating of the fluid is slower in the latter than in the former.

However, we can observe from Figures 7 and 9 that the concentration is not affected by Dufour effect in both cases of Ramped and constant boundary conditions. This is expected considering the settings of the governing Equations (6)-(8). The concentration Equation (8) is independent of Dufour parameter.

Figure 10 shows the influence of Dufour effect on the velocity over time. As $t$ increases, the velocity also increases and has higher value when the boundary conditions are constant, but has lower value with ramped wall conditions. This is because in the latter, the buoyancy force increases slowly as $t$ increases. Figure 11 shows that increase in $D_{f}$ causes the velocity to rise and apparently the time taken for the velocity to reach steady-state is very short compared to the work of Singh et al. [34]. 


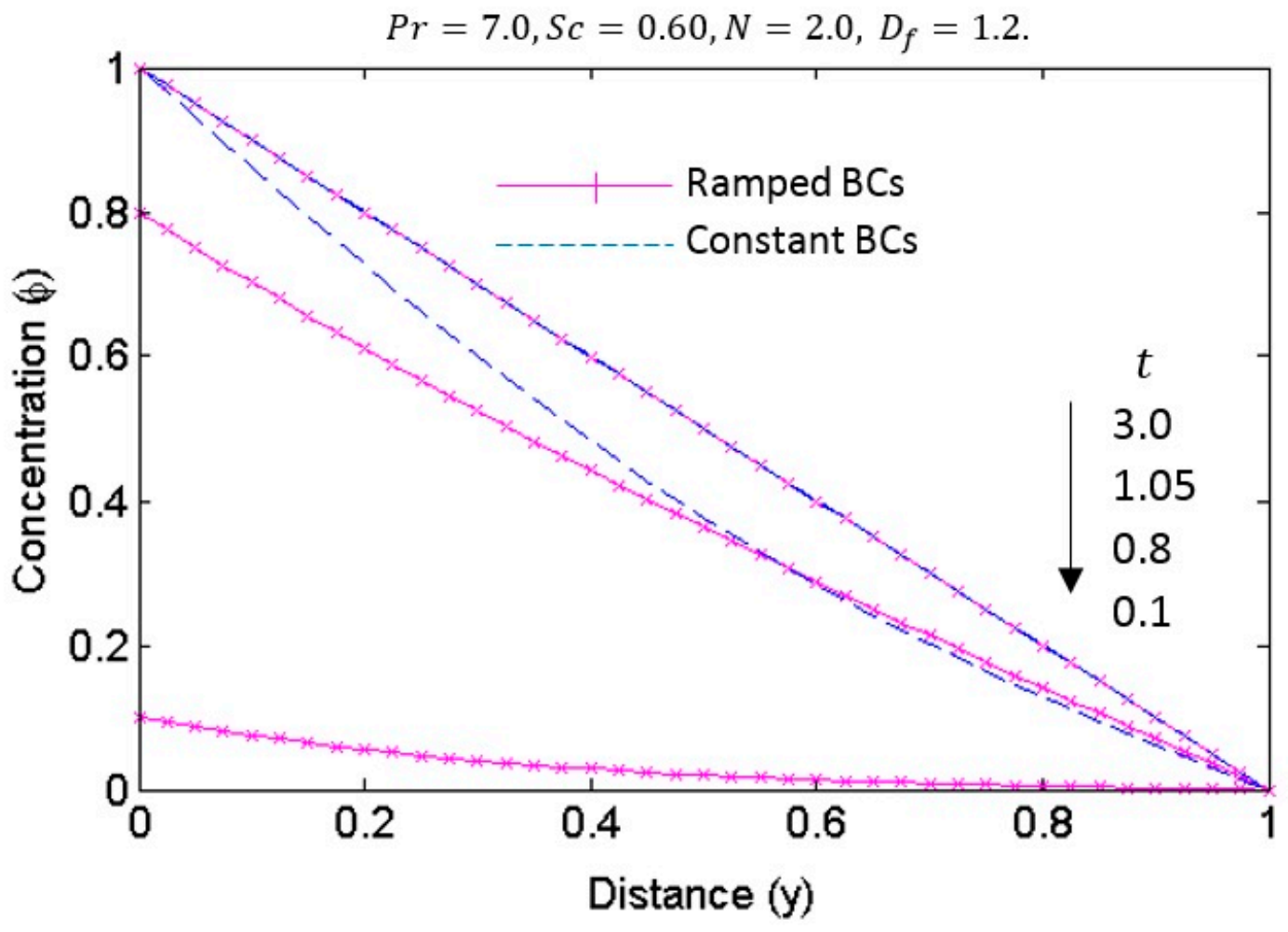

Figure 5. Concentration profile with ramped and constant boundary conditions.

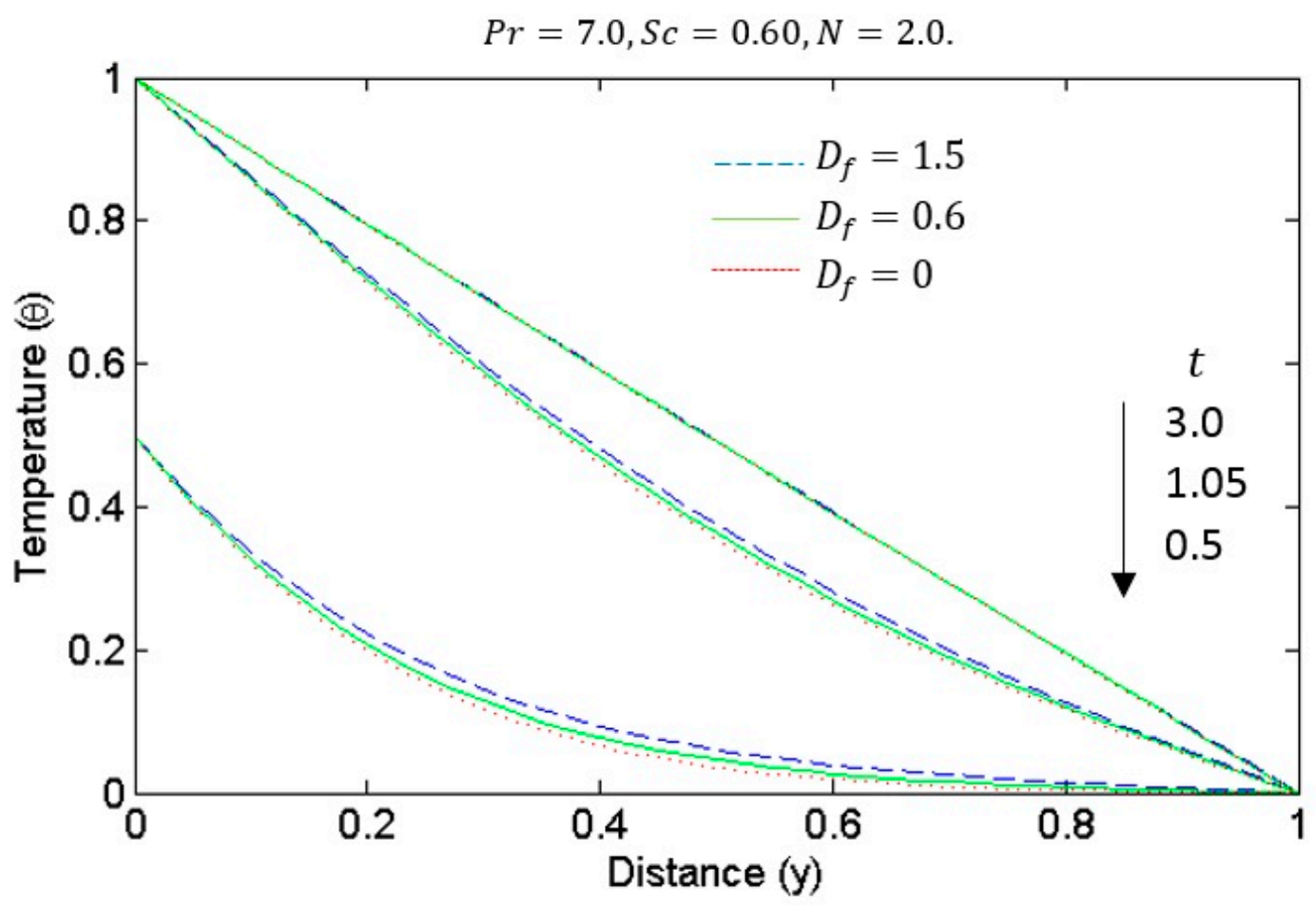

Figure 6. Dufour effect on the temperature with ramped wall boundary conditions. 


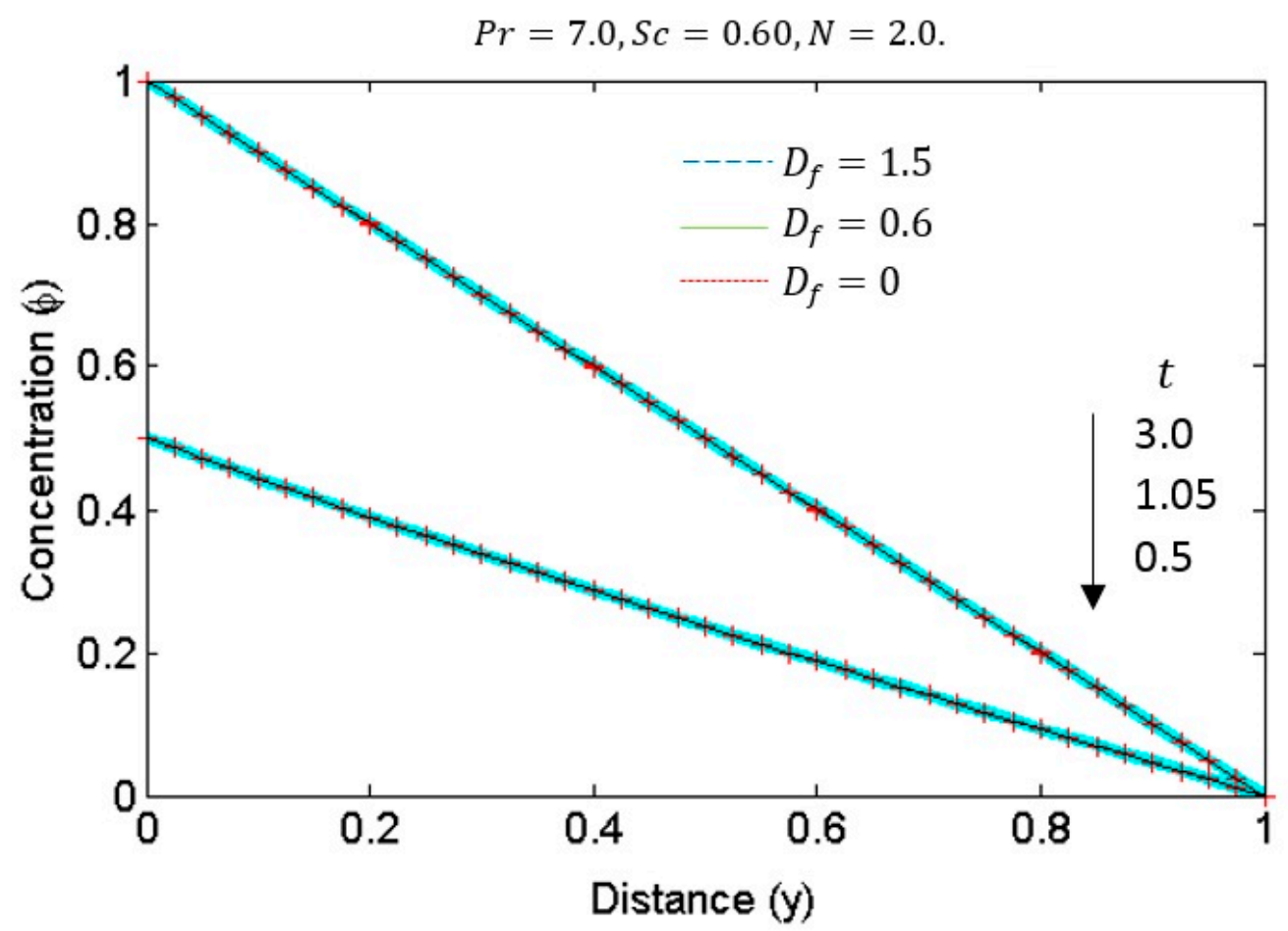

Figure 7. Dufour effect on the concentration with ramped wall boundary conditions.

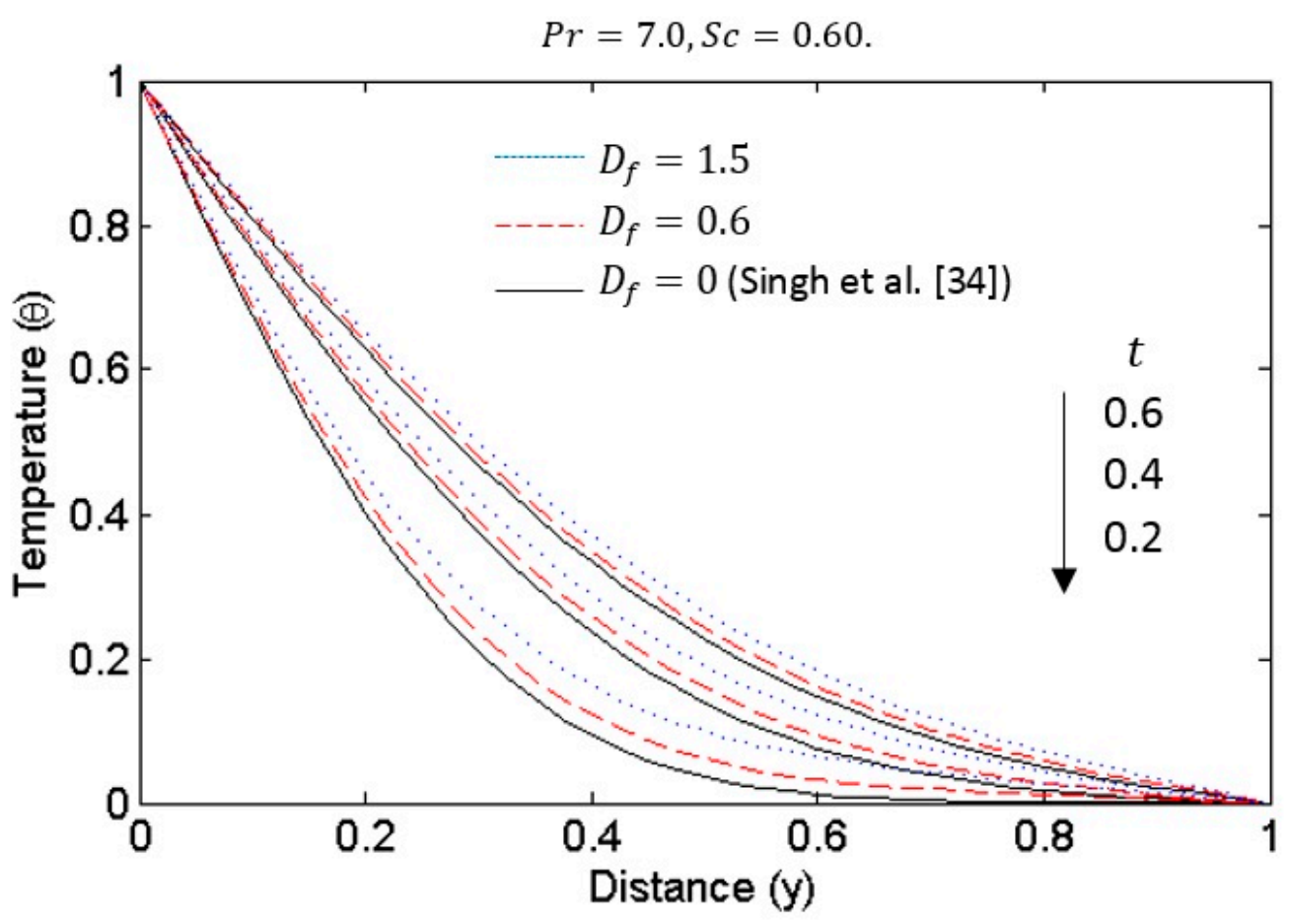

Figure 8. Dufour effect on the temperature with constant boundary conditions. 


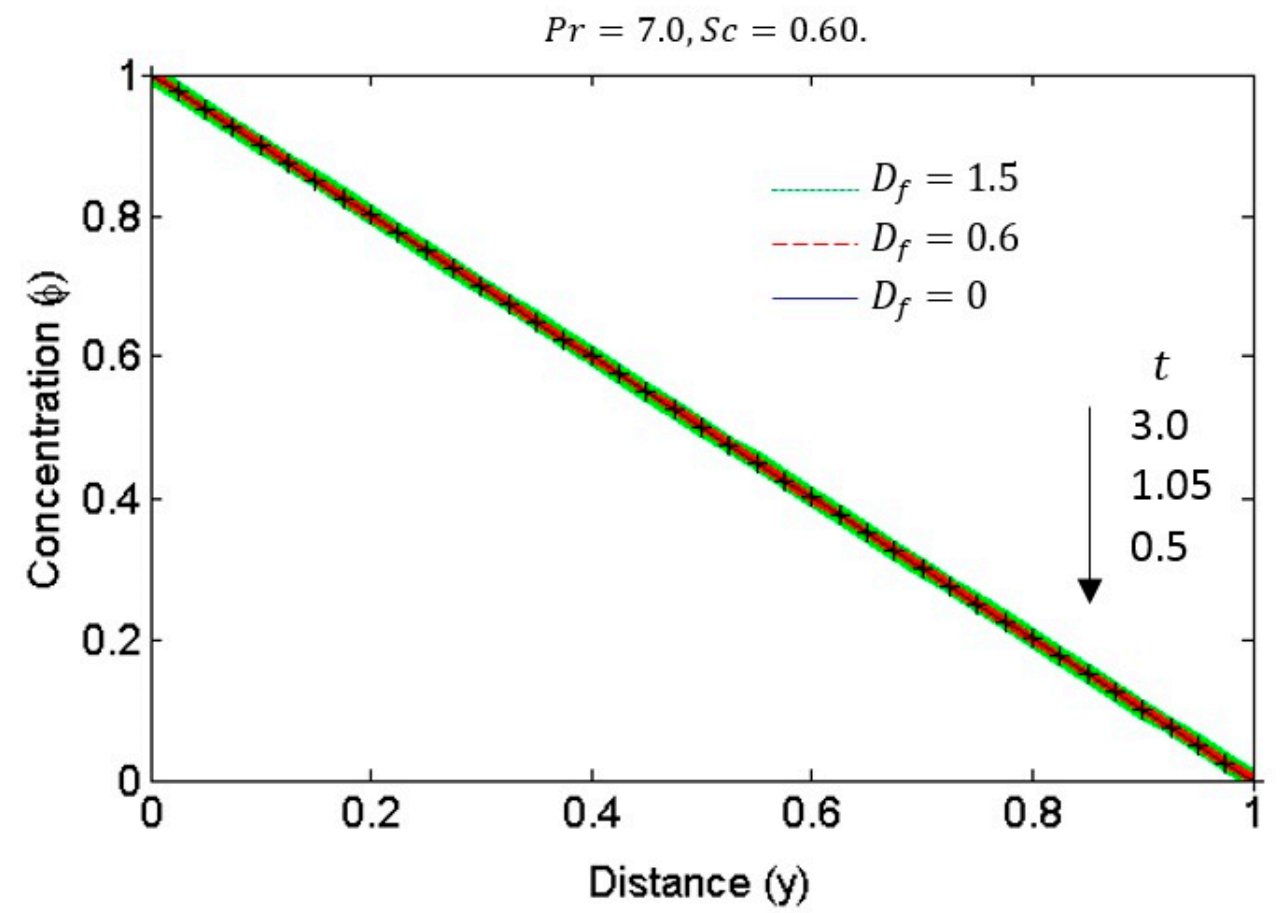

Figure 9. Dufour effect with constant boundary conditions.

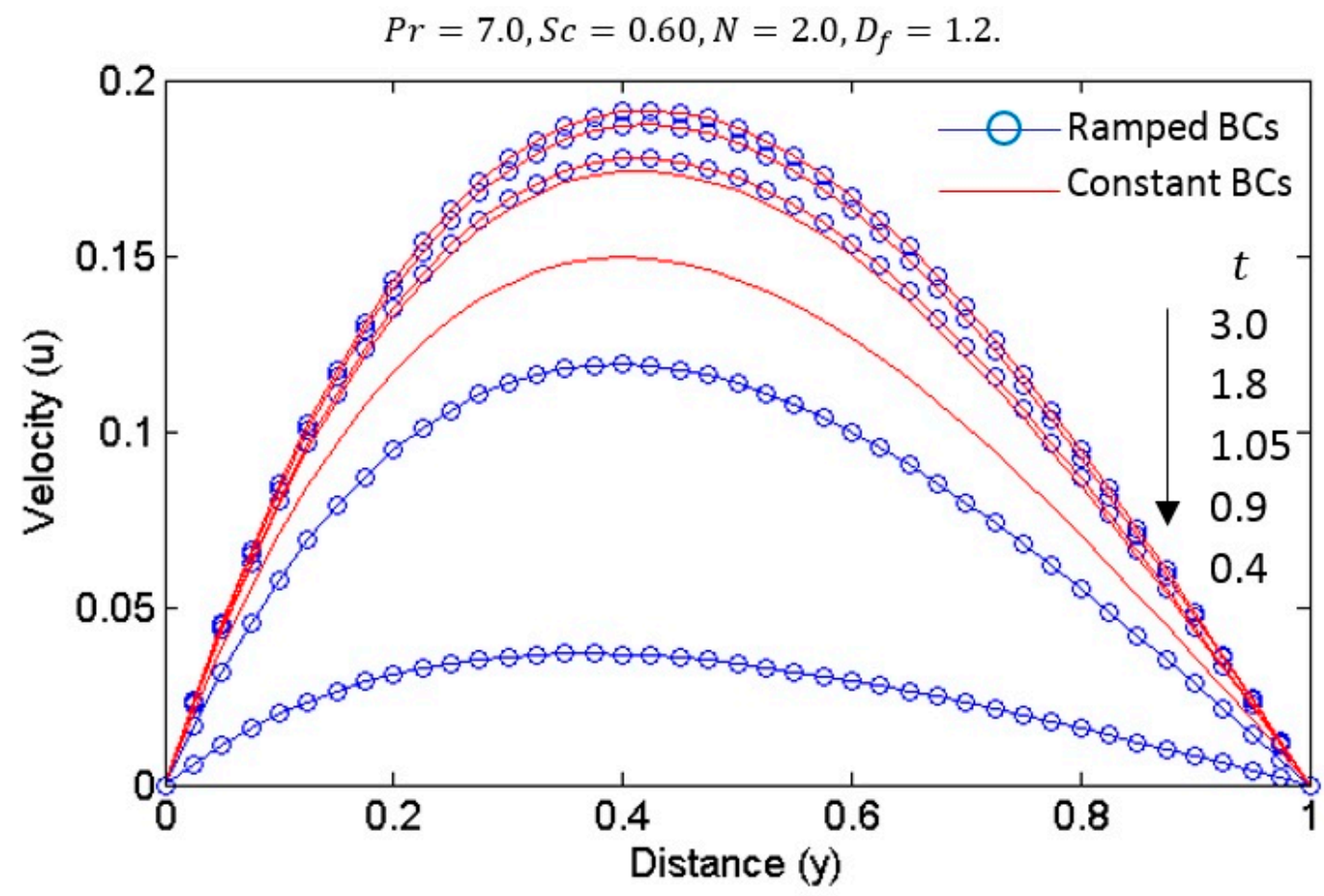

Figure 10. Velocity profile with ramped and constant boundary conditions. 


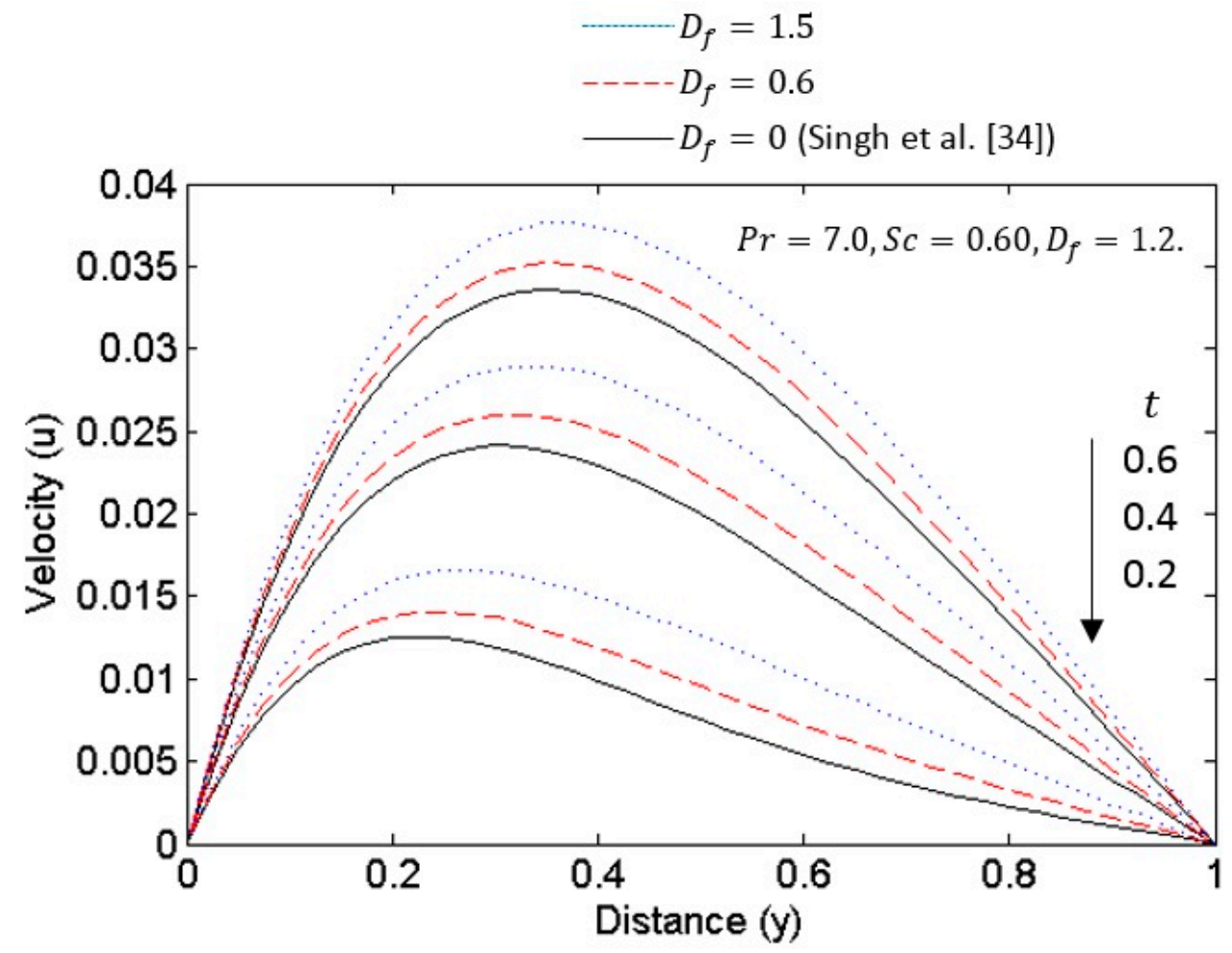

Figure 11. Dufour effect on the velocity profile with constant boundary conditions.

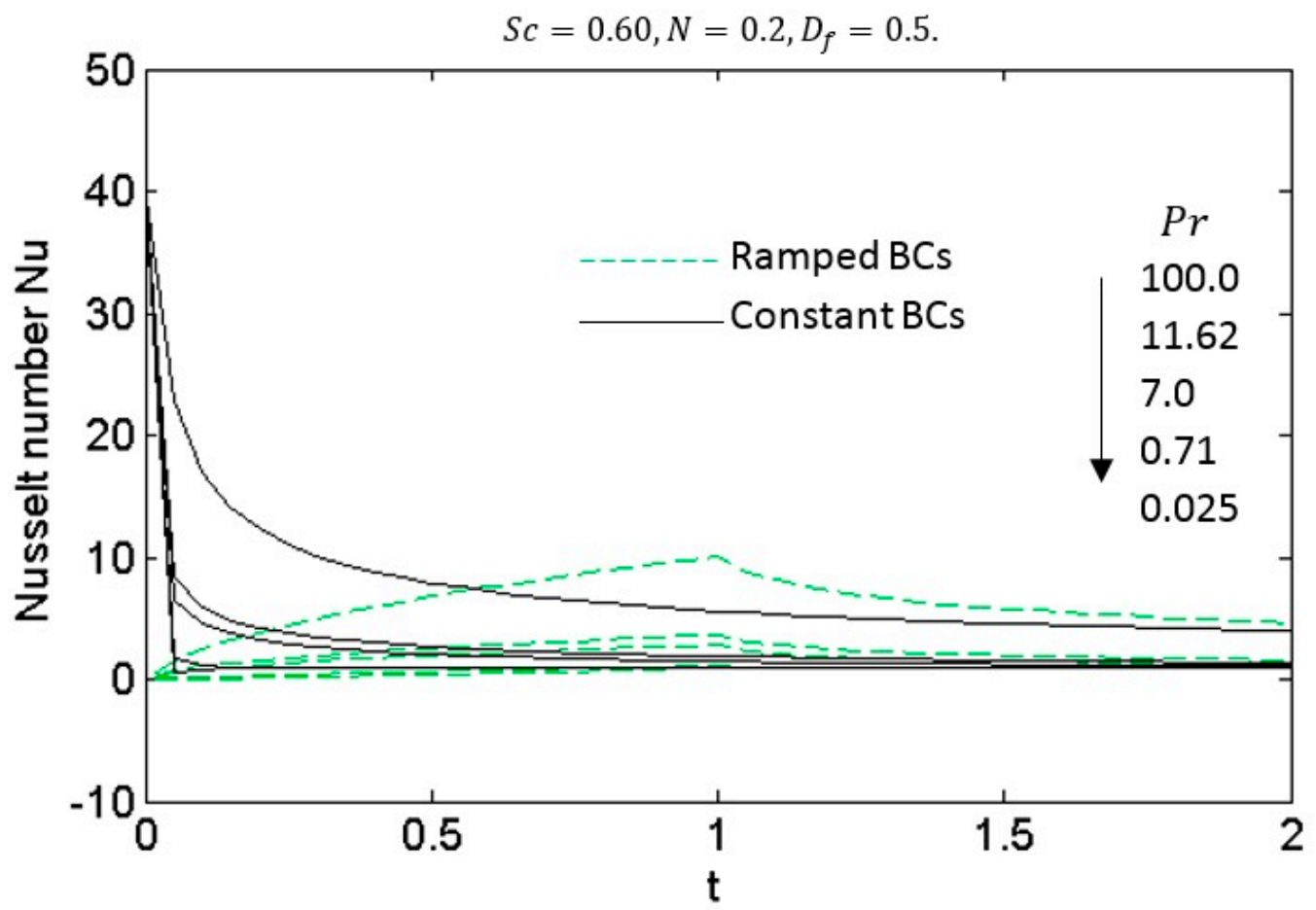

Figure 12. Nusselt number profile with ramped and constant boundary conditions. 
$N u, S h$ and $C_{f}$ are presented in Figures 12-14 respectively. $N u$ and $C_{f}$ depend on $P r$ and $t$ while $S h$ depends on $S c$ and $t$. From Figure 12, it is clear that for all $P r$ and with ramped boundary conditions, $N u$ ascends for $0<t \leq 1$ and descends when $t>1$. However, $N u$ decreases generally in the case of constant boundary conditions. Likewise, for all $S c$ and with ramped boundary conditions, $S h$ ascends for $0<t \leq 1$ and descends for $t>1$. Moreover, Sh decreases generally with constant boundary conditions. $C_{f}$ demonstrates an insignificant change over time for fluids with large Prandtl number $(\mathrm{Pr})$. However, $C_{f}$ variations become pretty responsive to minor change in time for fluids with smaller $\operatorname{Pr}$. Moreover, $C_{f}$ is higher in the case of constant boundary condition.

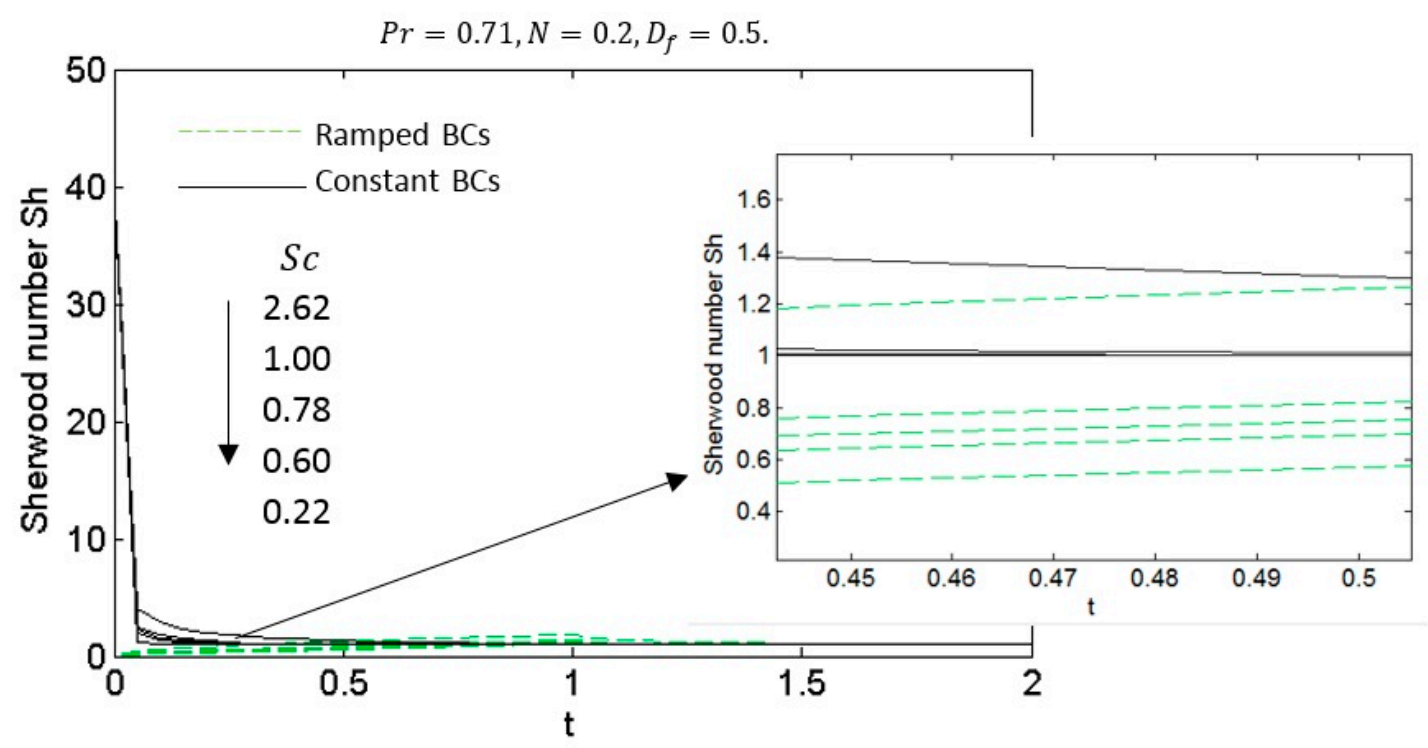

Figure 13. Sherwood number profile with ramped and constant boundary conditions.

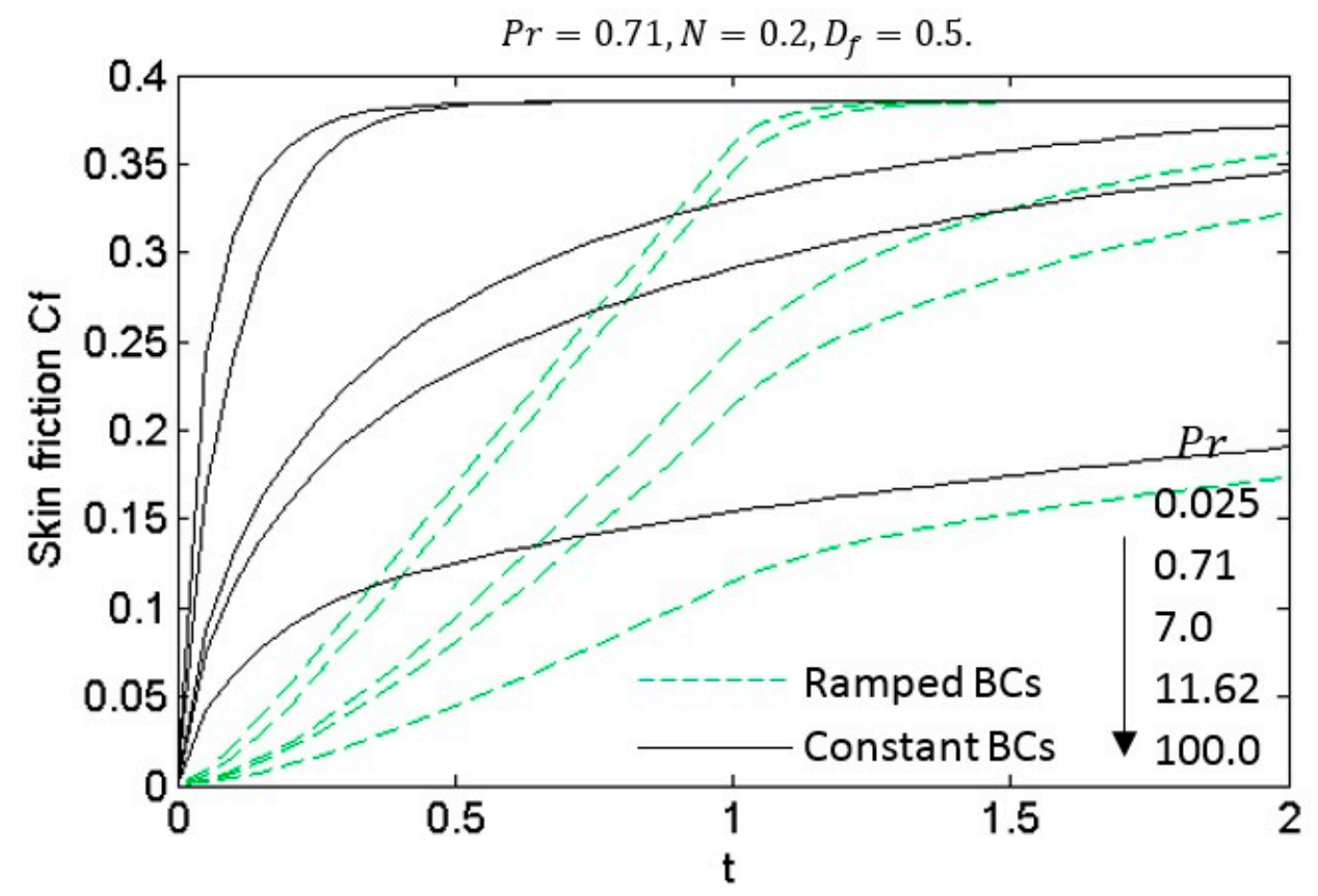

Figure 14. Coefficient of Skin-friction profile with ramped and constant boundary conditions. 


\section{Conclusions}

A mathematical model, that investigates the Dufour effect on unsteady free convection, and mass transfer flow of an incompressible fluid, through a vertical channel, in the presence of Dufour effect, has been developed. Influences of the ramped walls are analysed with various parameter values. The study shows that incorporating ramped BCs makes the fluid temperature, specie concentration, flow velocity, coefficient of rate of heat transfer, coefficient of rate of mass transfer and coefficient of Skin-friction to be lower compared to the case of constant BCs. Moreover, Dufour effect changes the fluid temperature. This happens because specie concentration gradient which occur as a combined effect of a permanent process can also generate heat flux. The velocity as well is affected by the Dufour effect. However, from the settings of the governing equations, the concentration cannot be influenced by the Dufour parameter. The results could have immediate relevance in the separation of isotopes, cooling of vertical printed circuit boards, geothermal systems and in the design of chemical processing equipment.

Author Contributions: Conceptualization, B.K.J. and Y.Y.G.; Data curation, Y.Y.G.; Formal analysis, Y.Y.G.; Investigation, Y.Y.G.; Methodology, B.K.J. and Y.Y.G.; Software, Y.Y.G.; Supervision, B.K.J.; Writing-original draft, Y.Y.G.; Writing-review \& editing, B.K.J. and Y.Y.G.

Funding: This research received no external funding.

Conflicts of Interest: The authors declare no conflict of interest.

\section{Nomenclature}

$C^{\prime} \quad$ Fluid specie concentration

$C_{0}^{\prime} \quad$ Fluid specie concentration near the wall $y^{\prime}=0$

$C_{l}^{\prime} \quad$ Fluid specie concentration near the wall $y^{\prime}=l$

$D_{m} \quad$ Coefficient of mass diffusivity

g Gravitational acceleration

$N \quad$ Buoyancy ratio

$l \quad$ Distance between the two walls

Pr Prandtl parameter

Sc Schmidt parameter

$D_{f} \quad$ Dimensionless Dufour number

$t^{\prime} \quad$ Dimensional time

$t_{0} \quad$ Ramped time

$t \quad$ Dimensionless time

$T^{\prime} \quad$ Fluid temperature

$T_{0}^{\prime} \quad$ Wall temperature at $y^{\prime}=0$

$T_{1}^{\prime} \quad$ Wall temperature at $y^{\prime}=l$

$D^{*} \quad$ Dimensional Dufour parameter

$u^{\prime} \quad$ Fluid velocity

$u \quad$ Dimensionless fluid velocity

$x^{\prime} \quad$ Axis along the wall at $y^{\prime}=0$

$y^{\prime} \quad$ Axis perpendicular to the walls

$y \quad$ Dimensionless axis in $y^{\prime}$-direction

$C_{f} \quad$ Coefficient of Skin-friction

$\mathrm{Nu} \quad$ Nusselt number

Sh Sherwood number

$H \quad$ Heaviside step function 


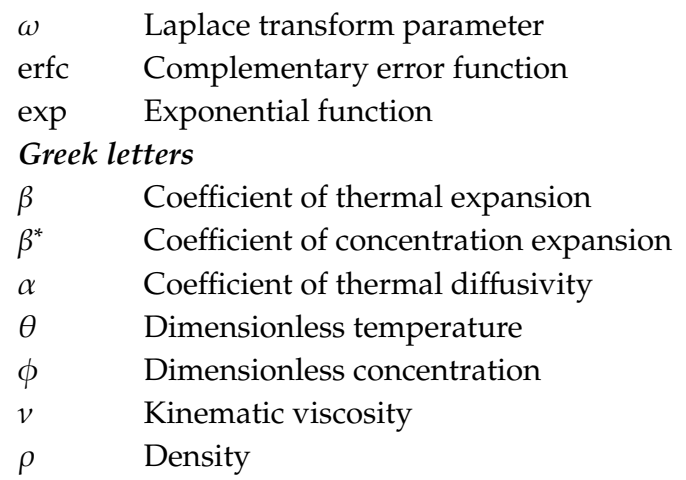

\section{References}

1. Jha, B.K.; Ajibade, A.O. Diffusion-Thermo Effects on Free Convective Heat and Mass Transfer Flow in a Vertical Channel with Symmetric Boundary Conditions. J. Heat Transf. 2011, 133, 052502. [CrossRef]

2. Florio, L.; Harnoy, A. Combination technique for improving natural convection cooling in electronics. Int. J. Sci. 2007, 46, 76-92. [CrossRef]

3. Manca, O.; Musto, M.; Naso, V. Experimental analysis of asymmetrical isoflux channel-chimney systems. Int. J. Sci. 2003, 42, 837-846. [CrossRef]

4. Rodrigues, A.M.; Da Piedade, A.C.; Lahellec, A.; Grandpeix, J. Modelling natural convection in a heated vertical channel for room ventilation. Build. Environ. 2000, 35, 455-469. [CrossRef]

5. Sudo, Y.; Kaminaga, M.; Minazoe, K. Experimental study on the effects of channel gap size on mixed convection heat transfer characteristics in vertical rectangular channels heated from both sides. Nucl. Eng. Des. 1990, 120, 135-146. [CrossRef]

6. Fossa, M.; Tanda, G. Frost formation in vertical channels under natural convection. Int. J. Multiph. Flow 2010, 36, 210-220. [CrossRef]

7. Umavathi, J.C.; Sheremet, M.A. Mixed convection flow of an electrically conducting fluid in a vertical channel using Robin boundary conditions with heat source/sink. Eur. J. Mech. B/Fluids 2016, 55, 132-145. [CrossRef]

8. Umavathi, J.; Sheremet, M.; Mohiuddin, S. Combined effect of variable viscosity and thermal conductivity on mixed convection flow of a viscous fluid in a vertical channel in the presence of first order chemical reaction. Eur. J. Mech. B/Fluids 2016, 58, 98-108. [CrossRef]

9. Chamkha, A.J. Unsteady laminar hydromagnetic fluid-particle flow and heat transfer in channels and circular pipes. Int. J. Heat Fluid Flow 2000, 21, 740-746. [CrossRef]

10. Ismael, M.A.; Pop, I.; Chamkha, A.J. Mixed convection in a lid-driven square cavity with partial slip. Int. J. Sci. 2014, 82, 47-61. [CrossRef]

11. Umavathi, J.C.; Chamkha, A.J.; Mateen, A.; Al-Mudhaf, A. Unsteady two-fluid flow and heat transfer in a horizontal channel. Heat Mass Transf. 2005, 42, 81-90. [CrossRef]

12. Narahari, M.; Sowmya, T.; Rajashekhar, P. Ramped temperature and Dufour effects on transient MHD natural convection flow past an infinite vertical plate in a porous medium. Eur. Phys. J. Plus 2015, 130, 251.

13. Kalidas, D. Magnetohydrodynamics Free Convection Flow of a Radiating and Chemically Reacting Fluid Past an Impulsively Moving Plate with Ramped Wall Temperature. J. Appl. Mech. 2012, 79, 061017.

14. Chamkha, A.J. On laminar hydromagnetic mixed convection flow in a vertical channel with symmetric and asymmetric wall heating conditions. Int. J. Heat Mass Transf. 2002, 45, 2509-2525. [CrossRef]

15. Magyari, E.; Chamkha, A.J. Combined effect of heat generation or absorption and first-order chemical reaction on micropolar fluid flows over a uniformly stretched permeable surface: The full analytical solution. Int. J. Sci. 2010, 49, 1821-1828. [CrossRef]

16. Umavathi, J.C.; Kumar, J.P.; Chamkha, A.J.; Pop, I. Mixed Convection in a Vertical Porous Channel. Transp. Porous Media 2005, 61, 315-335. [CrossRef] 
17. Chamkha, A.J.; Khaled, A.-R.A.; Khaled, A.A. Hydromagnetic combined heat and mass transfer by natural convection from a permeable surface embedded in a fluid-saturated porous medium. Int. J. Numer. Methods Heat Fluid Flow 2000, 10, 455-477. [CrossRef]

18. Chamkha, A.J. Double-diffusive convection in a porous enclosure with cooperating temperature and concentration gradients and heat generation or absorption effects. Numer. Heat Transf. Part A Appl. 2002, 41, 65-87. [CrossRef]

19. Ismail, Z.; Hussanan, A.; Khan, I.; Shafie, S. MHD and radiation effects on natural convection flow in a porous medium past an infinite inclined plate with ramped wall temperature: An exact analysis. Int. J. Appl. Math. Stat. 2013, 45, 77-86.

20. Umavathi, J.C.; Kumar, J.P.; Sheremet, M.A. Heat and mass transfer in a vertical double passage channel filled with electrically conducting fluid. Physica A 2017, 465, 195-216. [CrossRef]

21. Chamkha, A.J.; Mohamed, R.A.; Ahmed, S.E. Unsteady MHD natural convection from a heated vertical porous plate in a micropolar fluid with Joule heating, chemical reaction and radiation effects. Meccanica 2011, 46, 399-411. [CrossRef]

22. Magyari, E.; Chamkha, A. Exact analytical results for the thermosolutal MHD Marangoni boundary layers. Int. J. Sci. 2008, 47, 848-857. [CrossRef]

23. Alam, M.S.; Rahman, M.M.; Ferdows, M.; Kaino, K.; Mureithi, E.; Postelnicu, A. Diffusion-Thermo and Thermal-Diffusion Effects on Free Convective Heat and Mass Transfer Flow in a Porous Medium with Time Dependent Temperature and Concentration. Int. J. Appl. Eng. Res. 2007, 2, 81-96.

24. Eckert, E.R.G.; Drake, R.M. Analysis of Heat and Mass Transfer; McGraw-Hill: New York, NY, USA, 1972.

25. Ajibade, A.; Jha, B.K. Free convection heat and mass transfer flow in a vertical channel with the Dufour effect. Proc. Inst. Mech. Eng. Part E J. Mech. Eng. 2010, 224, 91-101.

26. Kafoussias, N.; Williams, E. Thermal-diffusion and diffusion-thermo effects on mixed free-forced convective and mass transfer boundary layer flow with temperature dependent viscosity. Int. J. Eng. Sci. 1995, 33, 1369-1384. [CrossRef]

27. Sheremet, M.A.; Sheremet, M. The influence of cross effects on the characteristics of heat and mass transfer in the conditions of conjugate natural convection. J. Eng. 2010, 19, 119-127. [CrossRef]

28. Reddy, P.S.; Chamkha, A.J. Soret and Dufour effects on $\mathrm{MHD}$ convective flow of $\mathrm{Al}_{2} \mathrm{O}_{3}-\mathrm{water}$ and $\mathrm{TiO}_{2}-$ water nanofluids past a stretching sheet in porous media with heat generation/absorption. Adv. Powder Technol. 2016, 27, 1207-1218. [CrossRef]

29. Narahari, M. Transient free convection flow between long vertical parallel plates with ramped wall temperature at one boundary in the presence of thermal radiation and constant mass diffusion. Meccanica 2012, 47, 1961-1976. [CrossRef]

30. Asma, K.; Ilyas, K.; Sharidan, S. Exact solutions for free convection flow of nanofluids with ramped wall temperature. Eur. Phys. J. Plus 2015, 130, 57.

31. Chandran, P.; Nirmal, C.S.; Ashok, K.S. Natural convection near a vertical plate with ramped temperature. Heat Mass Transf. 2005, 41, 459-464. [CrossRef]

32. Narahari, M.; Raghavan, V.R. Natural convection flow in vertical channel due to ramped wall temperature at one boundary. In Proceedings of the ASME 2009 Heat Transfer Summer Conference, San Francisco, CA, USA, 19-23 July 2009.

33. Narahari, M.; Tippa, S.; Pendyala, R.; Nayan, M. Ramped Temperature Effect on Unsteady MHD Natural Convection Flow Past an Infinite Inclined Plate in the Presence of Radiation, Heat Source and Chemical Reaction. In Recent Advances in Applied and Theoretical Mechanics; Hikari Ltd.: Rousse, Bulgaria, 2015; ISBN 978-1-61804-304-7.

34. Singh, A.K.; Gholami, H.R.; Soundalgekar, V.M. Transient free convection flow between two vertical parallel plates. Heat Mass Transf. 1996, 31, 329-333. [CrossRef]

35. Carslaw, H.S.; Jaeger, J.C. Conduction of Heat in Solids, 2nd ed.; Oxford University Press: Oxford, UK, 1959.

36. Carslaw, H.S.; Jaeger, J.C. Operational Methods in Applied Mathematics, 2nd ed.; Dover: New York, NY, USA, 1963. 
37. Abramowitz, B.M.; Stegun, I.A. (Eds.) Handbook of Mathematical Functions; Dover: New York, NY, USA, 1965.

38. Jithender, R.G.; Anand, R.J.; Srinivasa, R.R. Chemical reaction and radiation effects on MHD free convection from an impulsively started infinite vertical plate with viscous dissipation. Int. J. Adv. Appl. Math. Mech. 2015, 2, 164-176.

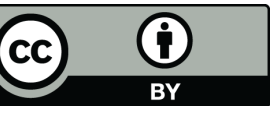

(C) 2019 by the authors. Licensee MDPI, Basel, Switzerland. This article is an open access article distributed under the terms and conditions of the Creative Commons Attribution (CC BY) license (http://creativecommons.org/licenses/by/4.0/). 